JURNAL PENDIDIKAN, p-ISSN 2715-095X, e-ISSN 2686-5041

Volume 30, No.1, Maret 2021 (73-80)

Online: http://journal.univetbantara.ac.id/index.php/jp

\title{
Nilai Kemandirian dalam Wacana Ungkapan Hikmah di SD Sekaresidenan Surakarta
}

\author{
Eko Purnomo ${ }^{1}$, Agus Budi Wahyudi ${ }^{2}$, dan Sawitri ${ }^{3}$ \\ 1,2Universitas Muhammadiyah Surakarta \\ ${ }^{3}$ Universitas Veteran Bangun Nusantara Sukoharjo \\ Email: a310170150@student.ums.ac.id, abw186@ums.ac.id,putrisawitriku@gmail.com
}

\begin{abstract}
Abstrak: Penelitian ini bertujuan mendeskripsikan nilai pendidikan karakter kemandirian dalam ungkapan hikmah di SD Sekaresidenan Surakarta. Penelitian ini menggunakan pendekatan deskriptif kualitatif. Data dalam penelitian ini ungkapan hikmah yang ditemukan di SD Sekaresidenan Surakarta. Sumber data penelitian ini adalah ungkapan hikmah di SD ekaresidenan Surakarta yang memiliki nilai pendidikan karakter kemandirian. Teknik pengumpulan data dalam penelitian ini yaitu teknik observasi, dokumentasi, dan catat. Metode analisis data yang digunakan adalah metode padan referensial. Teknik validasi data yang digunakan dalam penelitian ini menggunakan teknik trianggulasi teori yaitu dengan mencocokkan teori yang digunakan. Hasil penelitian menunjukkan bahwa dalam ungkapan hikmah di SD Sekaresidenan Surakarta mengandung nilai pendidikan karakter kemandirian antara lain etos kerja (kerja keras), tangguh tahan banting, daya juang, kreatif, dan menjadi pembelajar sepanjang hayat.
\end{abstract}

Kata-kata Kunci: Ungkapan hikmah, SD, Nilai pendidikan karakter kemandirian

\section{The Value of Independence in Discourse Expression of Wisdom in SD Sekaresidenan Surakarta}

\author{
Eko Purnomo $^{1,}$ Agus Budi Wahyudi', dan Sawitri ${ }^{3}$ \\ ${ }^{1,2}$ Universitas Muhammadiyah Surakarta \\ ${ }^{3}$ Universitas Veteran Bangun Nusantara Sukuharjo \\ Email:a310170150@student.ums.ac.id ${ }^{1}$, abw186@ums.ac.id²,putrisawitriku@gmail.com $^{3}$
}

\begin{abstract}
This study aims to describe the value of character education for independence in the expression of wisdom in SD Sekaresidenan Surakarta. This research use desciptive qualitative approach. The data in this study are expressions of wisdom found in SD Sekaresidenan Surakarta. The data source of this research is the expression of wisdom in SD Sekaresidenan Surakarta which has the value of character education for independence. Data collection techniques in this research are observation, documentation, and note taking techniques. The data analysis method used was the referential equivalent method. The data validation technique used in this study used the theoretical triangulation technique, namely by matching the theory used. The results showed that the expression of wisdom in SD Sekaresidenan Surakarta contains the value of character education for independence, including work ethic (hard work), resilience, fighting power, creative, and a lifelong learner.
\end{abstract}

Key Words: Words of wisdom, SD, Value of independence character education 


\section{Pendahuluan}

Karakter berkonsep nilai-nilai perilaku manusia yang berhubungan dengan Tuhan Yang Maha Esa, diri sendiri, sesama manusia, lingkungan, dan kebangsaan, yang terwujud dalam pikiran, sikap, perasaan, perkataan dan perbuatan berdasarkan norma-norma agama, hukum, tata krama, budaya dan adat istiadat (Sari, dkk, 2020: 148-149). Pendidikan karakter menjadi suatu keharusan di dunia pendidikan saat ini, guru mengharukan diri menenamkan nilai karakter dalam pendidikan. Hal ini dilaksanakan ketika pendidikan di lingkungan keluarga mulai abai dan dipercayakan pada lingkungan sekolah. Kondisi lingkungan sosial masyarakat juga semakin kehilangan kesadaran, bahwa perilaku sosial memberikan pengaruh besar pada individu. Oleh karena itulah, sekolah dalam hal ini guru menjadi frontliner dalam peningkatan mutu pendidikan karakter, budaya, dan moral (Wardani, 2010: 231). Dapat simpulkan bahwa guru di setiap sekolah memiliki tanggung jawab dalam pengembangan nilai karakter siswa. Di era pandemi Covid-19 siswa dan guru tidak dapat melakukan interaksi pembelajaran secara langsung.

Pembelajaran dilaksanakan secara daring. PJJ (daring) dapat melemahkan nilai karakter peserta didik. Peserta didik belajar di rumah, sedangkan orang tua sibuk dengan pekerjaannya. Hal ini diperkuat pendapat Purnomo \& Wahyudi (2020: 183) Selama pandemi Covid-19, perilaku kenakalan anak cenderung mengkhawatirkan, bahkan pada siswa Sekolah Dasar (SD). Kurangnya pengawasan guru dan orang tua menjadi salah satu faktor meningkatnya kenakalan pada anak SD. Seperti dijelaskan Baharun (2017:59-60) bahwa lulusan sekolah atau madrasah yang berprestasi tinggi pada mata pelajaran, cerdas, cemerlang, dan mampu memecahkan berbagai masalah dengan tepat, tetapi di sisi lain, siswa tidak menunjukkan karakter dan sikap yang baik.

Penanaman karakter sangat penting diberikan kepada peserta didik untuk menjadi insan yang memiliki akhlaq yang baik dalam kehidupan sehari-hari. Wardani, dkk. (2019:330) menyebutkan nilai-nilai seperti: rasa hormat, jujur, peduli, tanggung jawab, dan adil dapat menguatkan pendidikan karakter sehingga membantu peserta didik memahami, memperhatikan, dan menginterpretasi nilai-nilai yang baik dalam menjalankan kehidupan sehari-hari. Ungkapan hikmah terdiri atas dua kata, yaitu kata ungkapan dan kata hikmah. Kata ungkapan artinya sepadan dengan kata cetusan, ekspresi, letupan atau sederet kata adegium, aforisme, amsal, bidal, maksim, pepatah, peribahasa, perbahasaan, petitih, ibarat, misal, pengandaian, perumpamaan, dan idiom (Endarmoko, dalam Purnomo dan Wahyudi, 2020:184). Sedangkan kata hikmah sepadan dengan kata hikmat. Artinya 'kebijaksanaan, petunjuk; amanat, contoh, iktibar, kiasan, makna, pelajaran, teladan; afwah, berkat, keampuhan, kesaktian, pestaka, tuah, olah kesucian' (Endarmoko, dalam Purnomo dan Wahyudi, 2020:184). Jadi pengertian yang dikandung, bahwa ungkapan hikmah adalah kata-kata, baik itu paribahasa atau sejenisnya yang memiliki makna kata yang dapat digunakan sebagai petunjuk dalam kehidupan di dunia.

Erikson (dalam Susanti, dkk., 2020:1) mengatakan bahwa kemandirian adalah usaha untuk melepaskan diri dari orang tua dengan maksud anak menemukan dirinya melalui proses mencari identitas ego, yaitu merupakan perkembangan ke arah individualitas yang mantap dan berdiri sendiri. Kemandirian berasal dari kata mandiri yang berarti 'sikap dan perilaku yang tidak mudah tergantung pada orang lain dalam menyelesaikan tugas-tugasnya (Mustari dalam Khamid, 2020:30). Menurut beberapa orang bahwa karakter mandiri atau kemandirian adalah karakter di mana individu tidak selalu bergantung kepada individu 
lainnya, serta mampu berdiri sendiri. Arfiah \& Prasetya (2017:170) menyebutkan 3 (tiga) indikator kemandirian dalam penelitiannya yaitu sebagai berikut: a) Tidak bergantung pada orang lain dalam berbagai hal. b) Menyelesaikan tugas atau permasalahan tanpa merepotkan orang lain. c) Mampu mencukupi kebutuhannya dengan usaha sendiri. Penelitian tentang ungkapan hikmah dan pendidikan karakter telah dilakukan beberapa peneliti sebelumnya yaitu Lestari (2017:114-119), Lendari (2017:253-272), Santoso, dkk. (2019:63-79), Setiawaty, dkk. (2018:177-188), Yuliana, dkk. (2019:39-47), dan Samiaji (2019:295-308). Namun, beberapa penelitian sebelumnya tersebut belum pernah ada penelitian tentang nilai karakter kemandirian dalam ungkapan hikmah. Berdasarkan paparan yang sudah dijelaskan di atas, maka penelitian ini bertujuan untuk mendeskripsikan nilai pendidikan karakter kemandirian dalam ungkapan hikmah yang ada pada dinding SD Se-Karesidenan Surakarta.

\section{Metode Penelitian}

Jenis penelitian ini deskriptif kualitatif (Zurqoni, dkk,. 2019:884). Penelitian deskriptif yaitu menganalisis data yang berupa kata, frasa, dan kalimat dengan cara mendeskripsikan setiap data yang ditemukan. Data dalam penelitian ini ungkapan hikmah yang ditemukan di SD Se-Karesidenan Surakarta. Sumber data penelitian ini adalah ungkapan hikmah di SD-Se-Karesidenan Surakarta yang memiliki nilai pendidikan karakter kemandirian. Teknik pengumpulan data dalam penelitian ini yaitu teknik observasi, dokumentasi, dan catat. Metode analisis data yang digunakan adalah metode padan referensial. Metode padan referensial digunakan untuk menetukan identitas satuan kebahasaan menurut referen yang ditunjuk (Sudaryanto, 2018:15). Teknik validasi data yang digunakan dalam penelitian ini menggunakan teknik trianggulasi teori yaitu dengan mencocokkan teori yang digunakan yaitu teori nilai pendidikan karakter kemandirian.

\section{Hasil Penelitian}

Nilai kemandirian sesuai Kemendikbud (2016:9) nilai kemandirian etos kerja (kerja keras), tangguh tahan banting, daya juang, profesional, kreatif, keberanian, dan menjadi pembelajar sepanjang hayat. Ungkapan hikmah di SD Sekaresidenan Surakarta ditemukan nilai pendidikan karakter kemandirian (a) Etos Kerja (Kerja Keras), (b) Tangguh Tahan Banting, (c) Daya Juang, (d) Kreatif, dan (e) Belajar Sepanjang Hayat. Karakter profesional dan keberanian secara empiris belum dibutuhkan bagi seusia SD. Adapun kelima sub nilai kemandirian dijelaskan sebagai berikut: (1). Kerja keras adalah sikap dan perilaku yang ditunjukkan seseorang untuk memperoleh hasil yang maksimal dengan penuh semangat. Indikator karakter kerja keras menurut Kementrian Pendidikan Nasional (dalam Muryaningsih dan Mustadi, 2015:194), adalah untuk kelas 1-3 (kelas awal) adalah: mengerjakan semua tugas kelas dengan sungguh-sungguh, mencari informasi dari sumber di luar buku pelajaran, menyelesaikan PR pada waktunya, menggunakan sebagian besar waktu di kelas untuk belajar, dan mencatat dengan sungguh-sungguh sesuatu yang ditugaskan guru. Sedangkan indikator karakter kerja keras untuk kelas 4-6 (kelas tinggi) adalah: mengerjakan tugas dengan teliti dan rapi, mencari informasi dari sumber di luar sekolah, mengerjakan tugastugas dari guru pada waktunya, fokus pada tugas-tugas yang diberikan guru di kelas, dan mencatat dengan sungguh-sungguh sesuatu yang dibaca, diamati, dan didengar untuk kegiatan kelas. 


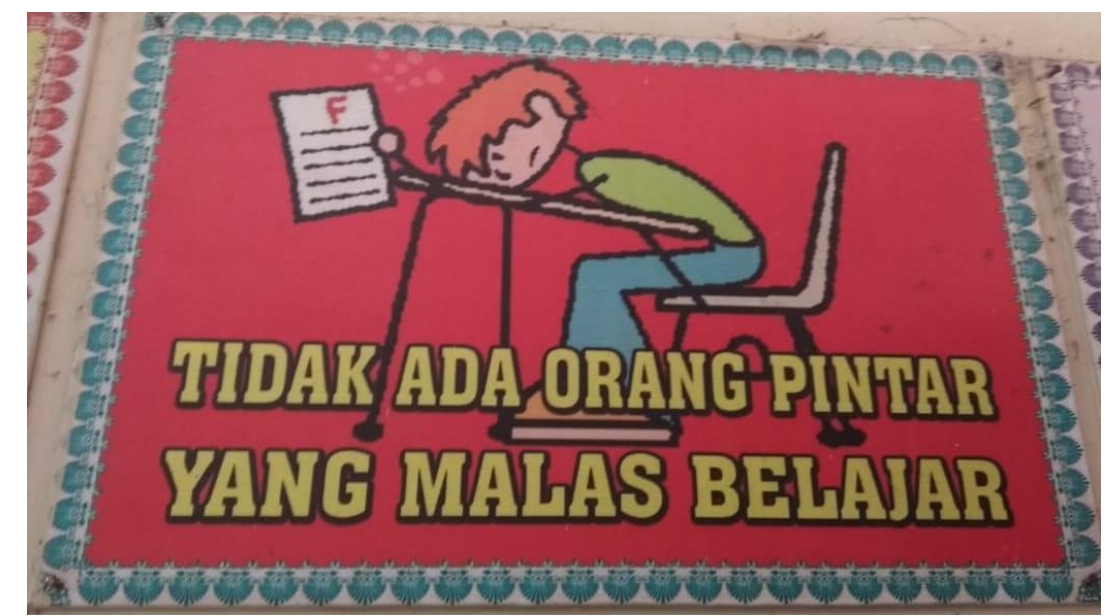

Gambar 1. Ungkapan Hikmah di SDN 02 Dukuh, Kabupaten Sukoharjo.

Etos kerja yang dimaksud di sini yaitu etos belajar yang berkaitan dengan anak usia SD yaitu giat belajar. Jika ingin menjadi pintar harus selalu rajin belajar. Tidak ada orang pintar yang malas belajar merupakaan ungkapan hikmah yang mengandung makna bahwa orang yang pintar, memiliki etos akan terus belajar. Semakin anak pintar, maka semakin tahu bahwa anak tak berilmu itu malas belajar. Selalu belajar merupakan salah satu karakter kerja keras yaitu berusaha untuk mendapatkan ilmu dengan sungguh-sungguh, serta penuh semangat. Belajar di usia anak SD yaitu selalu mengerjakan tugas, membaca buku pelajaran, dan latihan mengerjakan soal-soal. Anak menjauhi sikap bermalas-malas atau karena ingin bermain dengan teman-teman. Seperti dijelaskan Wuryanti \& Kartowagiran (2016: 235) bahwa kerja keras dapat dibentuk melalui latihan ketekunan untuk mencapai tujuan belajarnya. Semakin anak terus belajar semakin besar karakter kerja keras terbentuk dalam diri. (2). Tangguh adalah sikap dan karakter yang ditandai dengan pantang menyerah dalam menghadapi masalah apapun dan kuat dalam menghadapi semua rintangan. Karakter tangguh merupakan karakter yang mampu dengan mantap dan tidak tergoyahkan saat menghadapi beragam tantangan (Rai, dkk., 2018: 142).

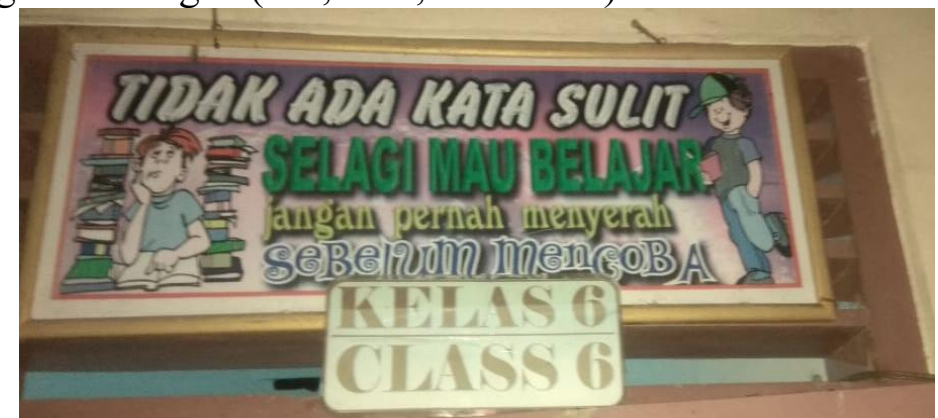

Gambar 2. Di SD Negeri 3 Jembungan, Kabupaten Boyolali.

Tangguh dan tahan banting yang dimaksud di sini yaitu semangat dalam belajar. Usia anak SD yaitu usia yang rentan bermalas-malasan dalam belajar, anak belum mencoba, tetapi sudah malas dan tidak mau belajar lagi. Tidak ada kata sulit selagi mau belajar, jangan pernah menyerah sebelum mencoba. Ungkapan hikmah tersebut bermakna bahwa sebagai seorang murid harus selalu terus belajar, jangan ada kata sulit sebelum mencoba. Ungkapan hikmah ini termasuk dalam karakter tangguh, sebab mengajarkan bahwa dalam melakukan sesuatu (belajar) jangan menyerah dahulu sebelum mencobanya. (3). Daya 
Juang. Peserta didik harus memiliki karakter daya juang yang tinggi. Daya juang adalah karakter untuk mencapai sesuatu dengan penuh semangat dan gigih. Sundari (2020:124) menyatakan bahwa daya juang siswa berperan penting dalam keberhasilan siswa bidang akademik.

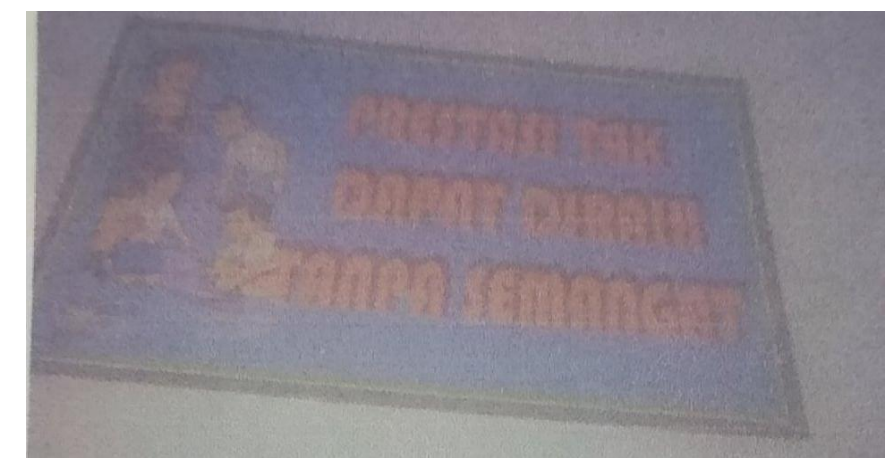

Gambar 3. SDN 01 Ngargoyoso, Kabupaten Karanganyar

Daya juang yang relevan untuk anak usia SD yaitu semangat dalam memperoleh ilmu/belajar. Anak usia SD yang menginginkan mendapat juara kelas, memenangkan perlombaan, meneruskan pendidikan lebih tinggi harus berjuang dengan gigih. Prestasi tak dapat diraih tanpa semangat. Ungkapan hikmah tersebut bermakna bahwa jika ingin melahirkan sebuah prestasi yang besar, maka butuh perjuangan yang besar pula. Ungkapan hikmah di atas termasuk dalam nilai pendidikan mandiri dengan daya juang yang besar. Untuk mencapai prestasi yang besar diperlukan semangat yang tinggi, semangat dalam mencari ilmu dan belajar. Apabila motivasi belajar semakin ditingkatkan, maka prestasi belajar yang dicapai siswa akan semakin baik (Mawarsih, dkk., 2013: 9-10). (4). Peserta didik perlu mempunyai karakter kreatif. Kreatif adalah kemampuan untuk menciptakan sesuatu yang baru yang unik dan mempunyai nilai guna. Balitbang (dalam Wahyuni \& Mustadi, 2016: 247) pendidikan budaya dan karakter bangsa disebutkan bahwa karakter kreatif bermakna berpikir dan melakukan sesuatu untuk menghasilkan cara atau hasil baru dari sesuatu yang telah dimiliki.

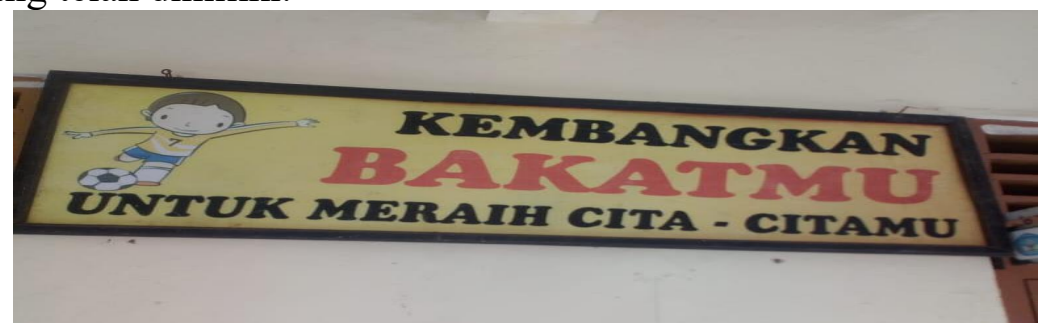

Gambar 4. Ungkapan Hikmah di SDN 02 Kembang, Kabupaten Boyolali

Anak usia SD adalah anak-anak yang mempunyai daya imajinasi yang kreatif. anak usia ini memiliki daya kreatif yang perlu dikembangkan. Kembangkan bakatmu untuk meraih cita-citamu. Ungkapan hikmah ini merupakan kalimat perintah untuk mampu mengembangkan bakat dalam diri peserta didik. Ungkapan hikmah tersebut termasuk dalam pendidikan karakter kreatif. Setiap individu mempunyai bakat-masing-masing. Orang yang mampu mengembangkan bakatnya termasuk orang yang memiliki kreativitas tinggi. Mengembangkan bakat termasuk sifat kreatif, misalnya: memiliki keahlian bermain sepak bola, bermain catur, dan mempunyai prestasi di bidang akademik. Bakat-bakat lain bisa ditambahkan, karena termasuk kegiatan yang mengasah kreativitas anak. (5). Belajar Sepanjang Hayat. Belajar adalah usaha yang dilakukan seseorang untuk memperoleh pengetahuan. Belajar sepanjang hayat merupakan sikap sesorang yang dapat dilihat dari 
aktivitasnya untuk selalu belajar memperoleh ilmu pengetahuan. Pendidikan sepanjang hayat atau pendidikan seumur hidup adalah sebuah sistem berelemen konsep-konsep pendidikan yang menerangkan keseluruhan peristiwa-peristiwa kegiatan belajar-mengajar yang berlangsung dalam keseluruhan kehidupan manusia (Wahyuddin, 2017:194).

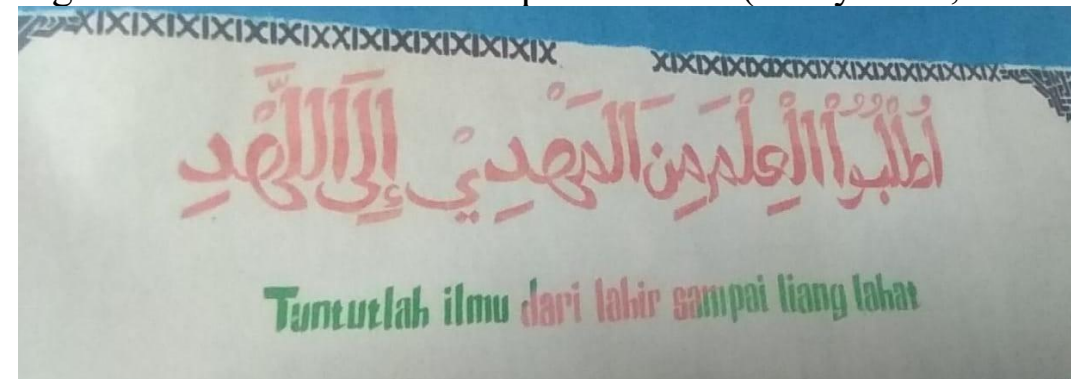

Gambar 5. Ungkapan Hikmah di MIM Blagung, Kabupaten Boyolali.

Belajar yang dimaksud yaitu anak usia SD setelah tamat SD, agar memiliki cita-cita untuk tetap melanjutkan pendidikan yang lebih tinggi SMP, SMA, Perguruan Tinggi. Belajar tidaklah hanya di bangku SD/sekolah formal saja, tetapi di manapun dapat belajar. Tuntutlah ilmu dari lahir sampai liang lahat. Ungkapan hikmah di atas merupakan kalimat perintah yang bernilai pendidikan karakter belajar sepanjang hayat. Agama Islam mengajarkan untuk selalu menuntut ilmu dari lahir sampai meninggal dunia. Ilmu yang dituntut tidaklah harus ilmu akademik, tetapi juga ilmu non-akademik. Ungkapan hikmah di atas bermakna bahwa belajar itu sepanjang hidup, tidak ada batasan usia dalam menuntut ilmu. Menurut Jarvis (dalam Hairani, 2018:362) memang, belajar sepanjang hayat merupakan kombinasi proses dalam keseluruhan hidup seseorang-baik jasmani (genetik, fisik, dan biologis) dan pikiran (pengetahuan, kecakapan, sikap, nilai, emosi keyakinan, dan perasaan) --situasi pengalaman sosial, ide/gagasan yang kemudian ditransformasikann secara kognitif, afektif, dan praktik (atau melalui beberapa kombinasi transformasi), dan diintegrasikan ke dalam biografi kehidupan seseorang yang menghasilkan perubahan atau pengalaman secara berkelanjutan.

\section{Pembahasan}

Ungkapan hikmah di SD/MI Se-Karesidenan Surakarta mengandung nilai pendidikan karakter kemandirian. Ungkapan hikmah dimaksudkan agar dibaca oleh peserta didik. berdasarkan teori yang dugunakan dalam penelitian ini, yaitu teori nilai pendidikan karakter kemandirian yang dikemukakan oleh Kemendikbud (2016:9), bahwa dalam ungkapan hikmah yang dipasang di SD/MI Sekaresidenan Surakarta sesuai dengan teori Kemendikbud. Nilai kemandirian yang ditemukan yaitu etos kerja (kerja keras), tangguh tahan banting, daya juang, kreatif, dan menjadi pembelajar sepanjang hayat. Adapun sub nilai pendidikan karakter kemandirian yang tidak ditemukan dalam penelitian ini yaitu professional dan keberanian. Anak SD memang belum dituntut profesional, karena baru mempelajari ilmu-ilmu dasar. Keberanian juga masih dalam taraf perkembangan belum begitu ditonjolkan dalam proses pendidikan dan pengajaaran di SD. Nilai pendidikan karakter kemandirian perlu diimplikasikan dalam pembelajaran jarak jauh masa pandemo Covid-19 oleh guru SD. Nilai kemandirian penting bagi peserta didik agar dalam kehidupan sehari-hari anak tidak selalu bergantung kepada orang lain. Budaya umpan balik dari peserta didik perlu dilaksanakan berkait dengan ungkapan hikmah yang telah disisipkan dalam pembelajaran jarak jauh. Guru memberikan kuis yang berinti pada butir-butir nilai yang telah ditemukan. Hal ini bisa dijadikan langkah nyata dalam penerapan penguatan pendidikan karakter kemandirian di SD. 


\section{Simpulan dan Saran}

Berdasarkan hasil dan pembahasan yang sudah diuraikan di atas, maka dapat disimpulkan bahwa dalam ungkapan hikmah di SD Se-Karesidenan Surakarta mengandung nilai pendidikan karakter kemandirian. Dari sebanyak 7 (tujuh) sub nilai pendidikan karakter kemandirian, hanya ditemukan 5 (lima) sub nilai pendidikan karakter kemandirian. Nilai pendidikan karakter kemandirian yang ditemukan yaitu antara lain etos kerja (kerja keras), tangguh tahan banting, daya juang, kreatif, dan menjadi pembelajar sepanjang hayat. Oleh karena itu, nilai karakter yang dicanangkan secara nasional sudah diterapkan dalam jenjang pendidikan SD. Penerapan dilakukan pihak sekolah, nilai pendidikan karakter kemandirian tertempel di dinding SD Sekaresidenan Surakarta, tetapi di masa pandemi Covid-19 ini ungkapan hikmah tidak bisa dibaca oleh peserta didik. Oleh karena itu, guru sebaiknya menyisipkan ungkapan hikmah di tengah-tengah pembelajaran jarak jauh saat ini. Ungkapan hikmah disisipkan dalam pembelajaran jarak jauh agar anak tetap membaca ungkapan hikmah yang mengandung nilai-nilai pendidikan karakter. Proses internalisasi dalam jiwa anak terjadi secara terus-menerus melalui penyisipan dalam pembelajaran.

\section{Daftar Rujukan}

Arfiah, S. \& Prasetya, A. (2017). Pembelajaran Kepramukaan dalam Penguatan Karakter Kemandirian dan Tanggung Jawab dalam Upaya Mempersiapkan Mahasiswa PPKn sebagai Pembina Ekstrakurikuler di Sekolah. URECOL, hal: 167-178.

Baharun, H. (2017). Total Moral Quality: A New Approach for Character Education in Pesantren. Ulumuna, 21(1), hal: 57-80.

Creswell, J. W. (2014). Research design: Qualitative, Quantitative, and Mixed Methods Approaches. America: United States of America.

Hairani, E. (2018). Pembelajaran Sepanjang Hayat Menuju Masyarakat Berpengetahuan. Tajdid: Jurnal Pemikiran Keislaman dan Kemanusiaan, 2(1), hal: 355-377.

Kementrian Pendidikan dan Kebudayaan. (2016). Konsep dan Pedoman Penguatan Pendidikan Karakter. Jakarta: Kementrian Pendidikan dan Kebudayaan RI.

Khamid, A. (2020). Model Pendidikan Karakter Kemandirian di Pondok Pesantren AlManar Kecamatan Tengaran Kabupaten Semarang dan Pondok Pesantren Anibros Kecamatan Suruh Kabupaten Semarang. Jurnal Inspirasi, Volume 4(1), hal: 25-40.

Lendari, H. (2017). Pendidikan Karakter Kemandirian bagi Perempuan dalam Novel Love Sparks in Korea Karya Asma Nadia (Pendekatan Analisis Gender). Jurnal Ilmiah Mahasiswa Raushan Fikr, volume 6(2), hal: 253-272.

Lestari, P. (2018). Urgensi Habituasi Nilai Karakter Kemandirian dan Tanggung Jawab Peserta Didik Sekolah Menengah Keguruan. Jurnal Ilmiah Ilmu Sosial, volume 4(2), hal: 114-119.

Mawarsih, S. E., Susiloningsih., \& Hamidi, N. (2013). Pengaruh Perhatian Orang Tua dan Motivasi Belajar Terhadap Prestasi Belajar Siswa SMA Negeri Jumapolo. JupeJurnal Pendidikan Ekonomi, volume 1(3),1-13.

Muryaningsih, S., \& Mustadi, A. (2015). Pengembangan rpp tematik-integratif untuk meningkatkan karakter kerja keras di kelas 1 sd n 2 sokaraja tengah. Jurnal Prima Edukasia, volume 3(2), hal: 190-201.

Purnomo, E., \& Wahyudi, A. B. (2020). Nilai Pendidikan Karakter dalam Ungkapan Hikmah di SD se-Karesidenan Surakarta dan Pemanfaatannya di Masa 
Pandemi. QALAMUNA: Jurnal Pendidikan, Sosial, dan Agama, volume 12(2), hal: 183-193.

Rai, N. G. M., Savitri, E. D., \& Ratu, A. (2018). Pengembangan Layanan Pusat Karir sebagai Strategi Membentuk Karakter yang Tangguh dalam Membangun Perencanaan Karir Mahasiswa Di Era Revolusi Industry 4.0. IPTEK Journal of Proceedings Series, (5), hal: 139-148.

Setiawaty, R., Wahyudi, A. B., Santosa, J., Sabardila, A., \& Kusmanto, H. (2018). Stiker Ungkapan Hikmah Sebagai Media Pemartabatan Karakter Anak Didik di Lingkungan Sekolah Muhammadiyah. Seminar Nasional Al-Islam dan Kemuhammadiyahan, hal: 177-188

Samiaji, M. H. (2019). Perkembangan Karakter Mandiri dan Jujur Pada Anak Usia Dini (Studi Kasus Anak-Anak KB Wadas Kelir Purwokerto Selatan). ThufuLA: Jurnal Inovasi Pendidikan Guru Raudhatul Athfal, volume 7(2), hal: 295-308.

Santoso, J., Wahyudi, A. B., Sabardila, A., Setiawaty, R., \& Kusmanto, H. (2019). Nilai Pendidikan Karakter Pada Ungkapan Hikmah Di Sekolah Dasar Se-Karesidenan Surakarta. Jurnal Pendidikan Karakter, (1), hal: 63-79.

Sari, N. K. S. K., Hutabarat, M. S., Susanti, E., \& Sopyan, M. (2020). Strategi Penanaman Karakter Islami pada Siswa MTS Swasta Al Manar Medan Johor (Studi Kasus Selama Pembelajaran Daring). Al-Ulum: Jurnal Pendidikan Islam, volume 1(2), hal: 247-164.

Sudaryanto. (2018). Metode dan Aneka Teknik Analisis Bahasa. Yogyakarta: Duta Wacana University Press.

Susanti, S., Imran, I., \& Ulfah, M. (2018). Penanaman Pendidikan Karakter Kemandirian Perilaku Santriwati melalui Metode Pembiasaan Pondok Pesantren Nurusshibyan Singkawang Tengah. Jurnal Pendidikan dan Pembelajaran Khatulistiwa, volume 9(12), hal: 1-10.

Wahyuddin, W. (2017). Pendidikan Sepanjang Hayat Menurut Perspektif Islam. SAINTIFIKA ISLAMICA: Jurnal Kajian Keislaman, volume 3(02), hal: 191208.

Wahyuni, M., \& Mustadi, A. (2016). Pengembangan Perangkat Pembelajaran Collaborative Learning Berbasis Kearifan Lokal untuk Meningkatkan Karakter Kreatif dan Bersahabat. Jurnal Pendidikan Karakter, volume 6(2), hal: 246-260.

Wardani, K. (2010, November). Peran Guru dalam Pendidikan Karakter Menurut Konsep Pendidikan Ki Hadjar Dewantara. In Proceeding of The 4th International Conference on Teacher Education; Join Conference UPI \&UPSI, hal: 8-10.

Wardani, L. S. P., Al-Ma'ruf, A. I., \& Prayitno, H. J. (2010). Nilai Karakter dalam Ungkapan Hikmah Bersumberkan Wacana Berita. Jurnal Analisa Sosiologi, volume 9, hal: $329-342$.

Wuryanti, U., \& Kartowagiran, B. (2016). Pengembangan Media Video Animasi untuk Meningkatkan Motivasi Belajar dan Karakter Kerja Keras Siswa Sekolah Dasar. Jurnal Pendidikan Karakter, volume 6(2), hal: 232-245.

Yuliana, W. D., Mahardhani, A. J., \& Utami, P. S. (2019). Pola Pendidikan Karakter Kemandirian Anak Berkebutuhan Khusus Tunanetra pada Panti Asuhan Tunanetra Terpadu Aisyiyah Ponorogo. Edupedia, volume 3(1), hal: 39-47.

Zurqoni, Z., Retnawati, H., Apino, E., \& Anazifa, R. D. (2019). Impact of Character Education Implementation: a Goal-Free Evaluation. Problems of Education in the 21st Century, 76(6), hal: 881-899. 